\title{
POPULARYZACJA BEZPIECZEŃSTWA I HIGIENY PRACY W KONTEKŚCIE WIELKOŚCI PRZEDSIĘBIORSTWA - WYNIKI BADAŃ
}

https://doi.org/10.33141/po.2019.07.06

\section{Katarzyna Boczkowska, Konrad Niziołek}

Przegląd Organizacji, Nr 7 (954), 2019, ss. 38-45 www.przegladorganizacji.pl @Towarzystwo Naukowe Organizacji i Kierownictwa (TNOiK)

\section{Wprowadzenie}

$\mathbf{P}$ roblem zapewnienia odpowiednich standardów bezpieczeństwa i higieny pracy jest jednym z głównych wyzwań, przed którymi stoją przedsiębiorcy na całym świecie. W Polsce od lat odnotowuje się znaczącą liczbę wypadków przy pracy, tj. 88330 osób w roku 2017 (o $0,5 \%$ więcej niż w 2016 r.) (GUS, 2018b), co skutkowało absencją 3110249 dni. Mimo malejącej nieznacznie wartości wskaźnika częstości wypadków przy pracy (od 7,07 w 2016 r. do 6,84 w 2017 r.) nadal w polskich firmach ginie codziennie 1 pracownik. Dramatycznie rośnie liczba ciężkich wypadków przy pracy (464 osób w 2016 r. do 661 osób w 2017 r.), Najczęstszą przyczyną wypadków jest tzw. błąd człowieka (human error), określany jako działanie pracownika odbiegające od wymaganych standardów i wymagań sytuacji (Reason, 1990). W Polsce niewłaściwe zachowanie pracownika stanowiło w roku 2017 ponad $75 \%$ przyczyn wypadków przy pracy (GUS, 2018b). Należy zatem poszukiwać skutecznych metod, które w centrum zainteresowania stawiają pracownika i jego zachowanie, budują odpowiednią kulturę bezpieczeństwa.

Zachęcanie pracowników do bezpiecznej pracy, kreowanie zachowań probezpiecznych, wspieranie programów bezpieczeństwa itp. uważane są za trwały, skuteczny czynnik sukcesu redukujący liczbę wypadków i urazów w miejscu pracy (Lai i in., 2011; Zohar i Luria, 2003).

Bezpieczeństwo pracy nabiera szczególnego znaczenia w sektorze małych i średnich przedsiębiorstw (MŚP). $Z$ badań wynika, że ryzyko wypadków i urazów w firmach MŚP jest większe niż w podmiotach dużych (Sørensen i in., 2007; Hasle i Limborg, 2006; Champoux i Brun, 2003; Fabiano i in., 2004). Niski poziom bezpieczeństwa i higieny pracy w MŚP jest zwykle przypisywany ich mniejszym zasobom ekonomicznym i ludzkim, co utrudnia tego typu przedsiębiorstwom przestrzeganie obowiązkowych wymogów bhp (Cagno i in., 2011).

W ciągu ostatnich dziesięcioleci coraz większe zainteresowanie w rozpoznawaniu krytycznych problemów bhp w MŚP wykazywali decydenci i naukowcy (Targoutzidis i in., 2014), choć zainteresowanie efektami implementacji przepisów bhp w sektorze MŚP, zwłaszcza firm mikro, nie podlegało analizom w ramach badań europejskich (Eurofound, 2015; European Agency, 2010).

W Polsce sektor MŚP objęty był badaniami dotyczącymi kultury bezpieczeństwa, które wykazały, że w przypadku sektora MŚP poziom kultury bezpieczeństwa jest zdecydowanie niższy niż w przypadku firm dużych (Znajmiecka-Sikora, 2014). W poszukiwaniu związków przyczynowo-skutkowych tego stanu autorzy niniejszego opracowania przeprowadzili analizę działań związanych z popularyzacją bhp, które to działania sprzyjają budowaniu wysokiej kultury bhp.

Celem niniejszego artykułu jest identyfikacja poziomu i form aktywności przedsiębiorstw w zakresie popularyzacji wiedzy o bhp i kształtowania postaw probezpiecznych w zależności od wielkości przedsiębiorstwa. Badania przeprowadzono na grupie 195 firm z wykorzystaniem metody PAPI. Postawiono następujące hipotezy badawcze:

H1: Poziom aktywności przedsiębiorstw w zakresie popularyzacji bhp jest skorelowany $\mathrm{z}$ wielkością przedsiębiorstwa.

H2: Wielkość przedsiębiorstwa determinuje aktywność pracowników i pracodawców w zakresie zgłaszanych uwag i pomysłów w obszarze bhp.

\section{Popularyzacja bezpieczeństwa i higieny pracy}

A by skutecznie podwyższać standardy bhp i kreować bezpieczne zachowania, należy podejmować działania wykraczające poza zapewnienie zgodności z przepisami prawa. Wiedza o zagrożeniach i przyczynach wypadków winna stanowić podstawę do działań korygujących i prewencyjnych, gdyż samo szkolenie pracowników często nie wystarczy. Konieczne jest inicjowanie przez pracodawców różnych form aktywności zachęcających pracowników do działań w utrzymaniu zdrowia i bezpieczeństwa własnego oraz innych osób.

Wielu autorów wskazuje na silny związek motywacji do bezpiecznej pracy z poziomem kultury bezpieczeństwa (Ejdys, 2016; Milczarek, 2002), bowiem motywowanie to proces wpływania na zachowanie pracowników za pośrednictwem takich bodźców, które zostaną przez niego przekształcone $\mathrm{w}$ działanie zgodne $\mathrm{z}$ celami organizacji (Kopertyńska, 2008). Z drugiej strony, wykreowanie wśród pracowników gotowości do pracy w sposób bezpieczny nie będzie skuteczne bez przekazania pracownikom informacji o działaniach profilaktycznych adekwatnych do zidentyfikowanych zagrożeń w miejscu pracy. Bardzo ważnym elementem jest również utrwalanie tej wiedzy, właściwy nadzór i komunikacja. Aspekty 
te wpisują się z kolei w zakres działań promocyjnych. Maksymalizacja wpływu działań promocyjnych związanych $\mathrm{z}$ bezpieczeństwem pracy wymaga więc znajomości podstaw marketingu, tak by zapewnić spójny komunikat przekazywany docelowym odbiorcom (tj. kierownictwu, pracownikom, innym).

Promocja ma dwa główne cele będące w zasadzie jej funkcjami: informacyjną i pobudzająca (Pabian, 2008). Do zadań promocji można zaliczyć: informowanie, przekonywanie, przypominanie (Werenowska, 2016) oraz komunikowanie się z klientem (Piratheepan i Pushpanathan, 2013). Dzięki celowym działaniom zwiększa się świadomość na temat produktów oraz stymuluje zainteresowanie zakupem produktu. W analogiczny sposób można podchodzić do promocji bezpieczeństwa i higieny pracy, której celem może być poprawa kultury bezpieczeństwa organizacji, tym samym obniżenie wypadkowości w firmie.

Aby promować i zwiększać świadomość zdrowotną i bezpieczeństwo wśród pracowników, przekaz musi być interesujący i atrakcyjny. Powinien być pozytywny, przyjemny i wykorzystujący komunikację między wszystkimi poziomami organizacji. Ponieważ postrzeganie zagrożenia i ryzyka związanego z pracą może wpływać na zachowanie pracownika, najlepsza (najbardziej przekonująca) komunikacja musi łączyć w sobie aspekty emocjonalne oraz racjonalne. Strategie promocyjne obejmują:

- misję, slogany i logotypy;

- opublikowane materiały (biblioteka, statystyki, biuletyny informacyjne);

- media, w szczególności: plakaty; wystawy, tablice ogłoszeń, zdjęcia zespołów ratunkowych, służb bhp, społecznych inspektorów pracy oraz raporty/wnioski z posiedzeń komisji/zespołów bhp; materiały audiowizualne; e-mail, Internet;

- seminaria i szkolenia (krótkie rozmowy, spotkania grupowe) (Ricci i in., 2016; Gembalska, 2017);

- kampanie specjalne: tydzień zdrowia i bezpieczeństwa (Vecchio-Sadus i Griffiths, 2004); promocja zdrowia (CDC, 2019; Du Plessis, 2013); zgłaszanie zdarzeń potencjalnie wypadkowych (near-miss) i badanie przyczyn źródłowych.

Prezentowany zestaw działań promocyjnych nie wyczerpuje katalogu działań, jakie mogą być podejmowane celem motywowania pracowników do bezpiecznej pracy.

Należy zaznaczyć, że w literaturze z zakresu bhp dość swobodnie i często zamiennie używa się aparatu pojęciowego motywacja oraz promocja bhp, co z oczywistych przyczyn może implikować błędy metodologiczne. $\mathrm{Z}$ tego też powodu autorzy niniejszego artykułu przyjęli pojęcie popularyzacja bhp, traktowane jako symbioza działań motywacyjnych i promocyjnych skierowanych na klienta wewnętrznego, jakim jest pracownik. Słuszność przyjętej terminologii potwierdzają przepisy polskiego prawa adresowane do pracowników służb bhp, zgodnie z którymi do zadań kadry bhp należy „inicjowanie i rozwijanie na terenie zakładu pracy różnych form popularyzacji problematyki bezpieczeństwa i higieny pracy oraz ergonomii” (Rozporządzenie, 2004).

\section{Metoda badawcza}

$\mathrm{N}$ a wstępie procesu badawczego dokonano wyboru firm w oparciu o kontakty własne - wygodny dobór próby (convenience sampling) (Dudovskiy, 2018). Badanie przeprowadzono w okresie od marca do maja 2018 roku przy użyciu metody PAPI na grupie 199 osób - reprezentantów przedsiębiorstw, z czego po weryfikacji prawidłowości i kompletności danych do dalszej analizy zakwalifikowano 195 jednostek.

Narzędziem badania był autorski kwestionariusz, w którym oprócz metryczki (6 pytań) znalazły się pytania merytoryczne dotyczące konsultacji z pracownikami zagadnień bhp (18 pytań) oraz aktywności organizacji $\mathrm{w}$ popularyzowaniu problematyki bhp (3 pytania).

W niniejszym artykule przedstawiono jedynie wybrane aspekty będące częścią badań szerszych (Boczkowska, Niziołek, 2018) dotyczących zaangażowania i partycypacji pracowniczej w obszarze bhp ${ }^{1}$. Skoncentrowano się na następujących pytaniach:

1. Jakie formy popularyzacji bhp podejmowane są w Pani/a firmie?

2. Czy w Pani/a firmie zgłaszane są i analizowane są uwagi/sugestie/pomysły pracowników w obszarze bhp?

Pierwsze pytanie miało charakter pytania otwartego, drugie pytanie było zamknięte $\mathrm{z}$ warunkową możliwością rozwinięcia w formie otwartej. Pytania nie dotyczyły opinii, lecz faktów, tj. czy w przedsiębiorstwach podejmowane są jakiekolwiek działania w zakresie popularyzacji bezpieczeństwa i higieny pracy. Dobór 195 respondentów $\mathrm{z}$ różnych podmiotów gospodarczych obrazował skalę aktywności na rzecz bhp występujących w różnorodnych formach i wykorzystujących rozmaite środki.

Otwarta forma pytań dawała respondentom możliwość swobodnej wypowiedzi. Wszystkie wywiady zostały zarejestrowane, transkrybowane, zakodowane i pogrupowane w odpowiednie kategorie.

Weryfikacja postawionych hipotez została przeprowadzona $\mathrm{z}$ wykorzystaniem testu niezależności $\chi^{2}$ oraz testu parametrycznego dla wskaźników struktury, które przeprowadzono z wykorzystaniem programu Statistica 13 PL.

\section{Charakterystyka próby badawczej}

D odmiotem badań byli pracownicy zatrudnieni na stanowiskach inżynieryjno-technicznych $(\mathrm{n}=37)$, administracyjno-biurowych $(\mathrm{n}=87)$, robotniczych $(\mathrm{n}=15)$, kierowniczych $(\mathrm{n}=35)$, służb bhp $(\mathrm{n}=3)$ oraz innych $(\mathrm{n}=18)$. Informacje pozyskane $\mathrm{z}$ metryczki odnośnie do badanych podmiotów syntetycznie przedstawiono w tabeli 1 .

Średni czas funkcjonowania badanych firm na rynku to 27 lat. Średni straż pracy respondentów wynosił 6 lat, staż na zajmowanym stanowisku wahał się w przedziale od 1 miesiąca do 19 lat.

Najczęściej reprezentowany był sektor przetwórstwa przemysłowego $(25,1 \%)$, działalności finansowej $(7,7 \%)$ oraz pozostałej działalności usługowej $(29,2 \%)$. W badanej grupie nie było przedstawicieli rolnictwa, górnictwa oraz gospodarki wodnej. 
Tabela 1. Charakterystyka grupy badawczej

\begin{tabular}{|c|c|c|c|c|c|}
\hline Staż pracy respondentów & $N=195$ & $\begin{array}{c}\% \\
\text { w grupie }\end{array}$ & Wielkość firmy & $N=195$ & $\begin{array}{c}\% \\
\text { w grupie }\end{array}$ \\
\hline do 1 roku & 50 & $25,64 \%$ & Małe liczba pracowników <50 osób & 64 & $32,8 \%$ \\
\hline $1-5$ lata & 121 & $62,05 \%$ & Średnie liczba pracowników 50-250 osób & 33 & $16,9 \%$ \\
\hline $6-10$ lat & 19 & $9,74 \%$ & \multirow{3}{*}{ Duże liczba pracowników >250 osób } & \multirow{3}{*}{98} & \multirow{3}{*}{$50,3 \%$} \\
\hline $10-15$ lat & 3 & $1,54 \%$ & & & \\
\hline powyżej 15 lat & 2 & $1,03 \%$ & & & \\
\hline
\end{tabular}

Źródło: opracowanie własne

\section{Wyniki badań}

\section{Inicjatywy na rzecz popularyzacji bhp - ocena jakościowa}

pośród 195 badanych jedynie w 69 przypadkach (35,4\%) podjęto działania związane $\mathrm{z}$ popularyzacją bezpieczeństwa pracy. Respondenci ci wskazali sumarycznie 83 różne inicjatywy zgrupowane w 14 kategoriach (rys. 1).

Największą popularnością $(n=15 ; 22 \%)$ cieszyło się zgłaszanie przez pracowników uwag/sugestii/pomysłów w obszarze bhp, w tym w ramach programów Kaizen, następnie akcje informacyjne w postaci plakatów/haseł o tematyce bhp $(\mathrm{n}=12 ; 19 \%)$, konkursy bhp $(\mathrm{n}=12 ; 17 \%)$ oraz dodatkowe szkolenia/kursy $(\mathrm{n}=11 ; 16 \%)$. Wyniki uzyskane w grupie badanych prezentuje rysunek 1 .

Podejmowanym w przedsiębiorstwach inicjatywom popularyzującym bhp $(\mathrm{n}=69)$, w niespełna połowie przypadków $(\mathrm{n}=35)$, towarzyszyły działania o charakterze motywacyjnym. Respondenci wskazali na funkcjonowanie systemu kar/nagród w obszarze zaangażowania pracowników w działania na rzecz bhp, co przedstawia rysunek 2 .

W ramach systemu (rys. 2) najczęściej wskazano nagrody rzeczowe $(n=16)$, finansowe $(n=8)$ oraz punkty, które brane są pod uwagę podczas oceny pracowniczej czy też awansu $(\mathrm{n}=8)$. Z powyższych danych wynika, że badane przedsiębiorstwa preferują pozytywne wzmocnienie pracowników w obszarze bhp, bowiem stosowanie kar to zaledwie $6 \%$.

\section{Popularyzacja bhp a wielkość przedsiębiorstwa}

W celu weryfikacji hipotezy $\mathrm{H} 1$ dokonano analizy podejmowania przez przedsiębiorstwa działań popularyzacyjnych bhp w zależności od wielkości firmy, uwzględniając podział na przedsiębiorstwa: małe, średnie i duże. Jako miarę zależności wykorzystano współczynnik kontyngencji C-Pearsona (ang. Pearson's C contingency coefficient) w oparciu o utworzoną tabelę kontyngencji

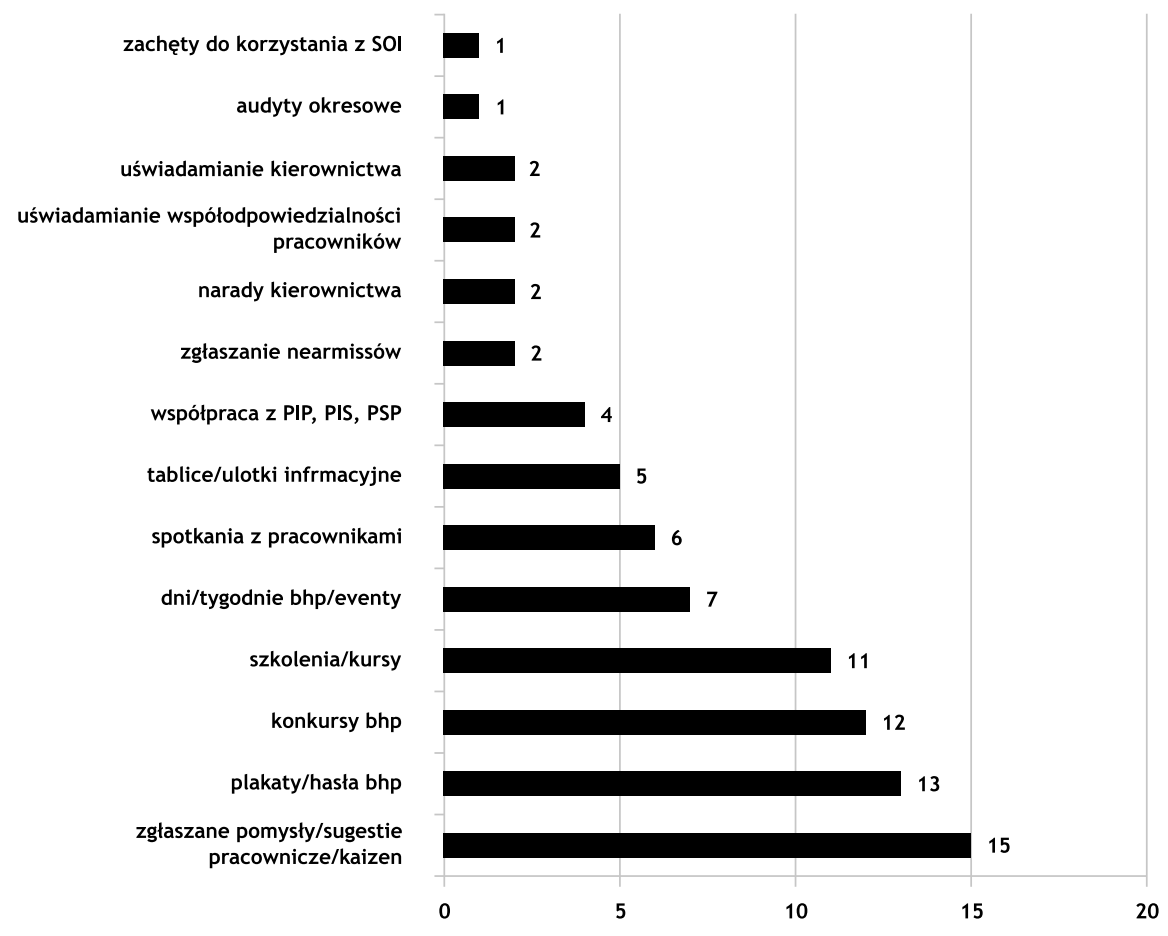

Rys. 1. Formy popularyzacji bezpieczeństwa i higieny pracy wśród respondentów Źródto: opracowanie wtasne 
(tab. 2). Otrzymana wartość statystyki $\chi^{2}=35,19$ oraz wyznaczona dla niej wartość p, wskazują na istnienie statystycznie istotnej zależności pomiędzy wielkością przedsiębiorstwa a aktywnością w obszarze popularyzacji bhp.

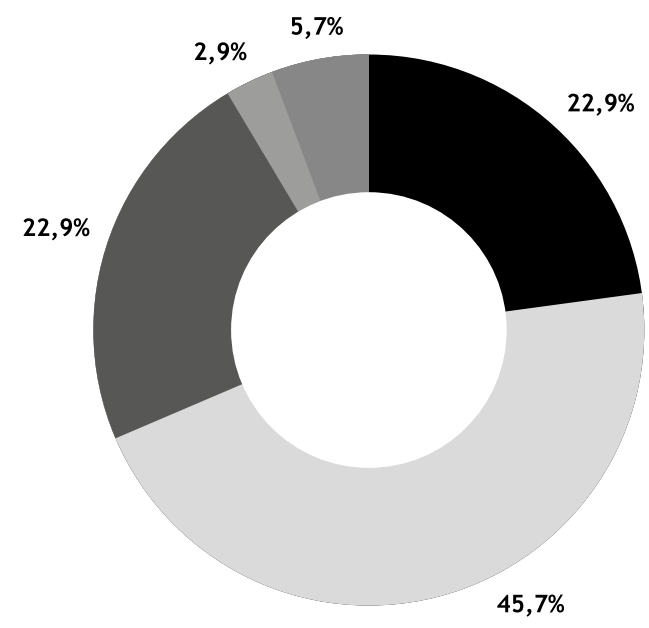
nagrody finansowe
pochwała
nagrody rzeczowe
kary
punkty w ocenie pracowniczej

Rys. 2. System kar/nagród w obszarze dziatań na rzecz bhp Źródło: opracowanie wtasne
W celu porównania poziomu podejmowanych w przedsiębiorstwach aktywności w obszarze popularyzacji bhp, przy uwzględnieniu wielkości firmy (małe - M, średnie - Ś, duże - D), zastosowano test parametryczny weryfikujący hipotezę o równości dwóch wskaźników struktury. Dla każdej pary M-Ś, M-D, Ś-D przeprowadzono analizę porównawczą, dane i wyniki zestawiono w tabeli 3 oraz na rysunku 3.

$\mathrm{Z}$ analizy tabeli 3 wynikają istotne statystycznie różnice pomiędzy wszystkimi trzema grupami $(\mathrm{p}<0,005)$. Uprawnione jest zatem stwierdzenie, że $\mathrm{w}$ przedsiębiorstwach dużych działania popularyzujące w obszarze bhp podejmowane są częściej niż w średnich. Najmniejszą aktywność w tym zakresie wykazują firmy małe.

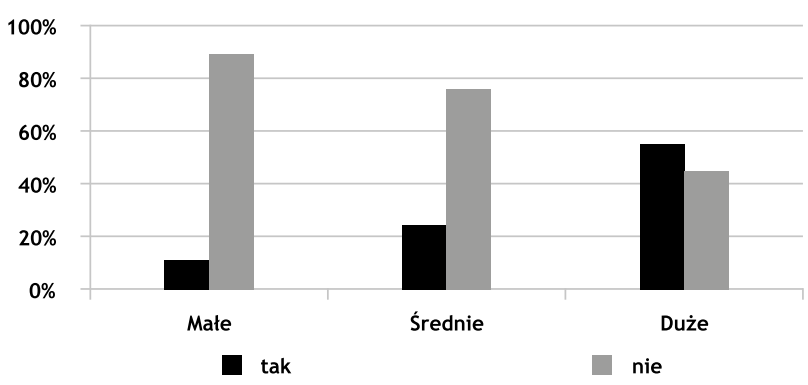

Rys. 3. Interpretacja graficzna dziatań popularyzacyjnych w obszarze bhp w kontekście wielkości organizacji

Źródło: opracowanie własne

Tabela 2. Tabela kontyngencji i statystyka $x^{2}$ działań popularyzujących bhp a wielkość organizacji

\begin{tabular}{|c|c|c|c|}
\hline \multirow{2}{*}{ Wielkość firmy } & \multicolumn{2}{|c|}{ Działania popularyzacyjne podejmowane przez przedsiębiorstwo } & \multirow{2}{*}{ Suma } \\
\hline & nie & tak & \\
\hline Małe & 57 & 7 & 64 \\
\hline Średnie & 25 & 8 & 33 \\
\hline Duże & 44 & 54 & 98 \\
\hline Suma & 126 & 69 & 195 \\
\hline statystyka & Chi-kwadrat & df & $\mathrm{p}$ \\
\hline $\mathrm{Chi}^{\wedge} 2$ Pearsona & 35,18531 & $\mathrm{df}=2$ & $\mathrm{p}=0,00000$ \\
\hline
\end{tabular}

Źródto: opracowanie własne

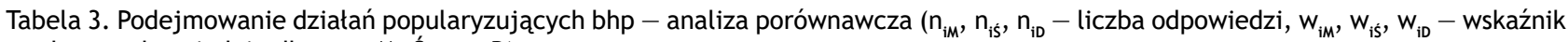
struktury odpowiednio dla grup $M$, Ś oraz D)

\begin{tabular}{|c|c|c|c|c|c|c|}
\hline \multirow{3}{*}{$\begin{array}{l}\text { Porównanie } \\
\text { grup M-Ś }\end{array}$} & odpowiedź & $n_{\mathrm{iM}}$ & $w_{\mathrm{iM}}$ & $n_{\mathrm{iS}}$ & $w_{\mathrm{i} \hat{\mathrm{S}}}$ & $\mathrm{p}<0,05$ \\
\hline & tak & 7 & $10,94 \%$ & 8 & $24,24 \%$ & \multirow{2}{*}{0,042981} \\
\hline & nie & 57 & $89,06 \%$ & 25 & $75,76 \%$ & \\
\hline \multirow{3}{*}{$\begin{array}{l}\text { Porównanie } \\
\text { grup M-D }\end{array}$} & odpowiedź & $n_{\mathrm{iM}}$ & $w_{\mathrm{iM}}$ & $n_{\mathrm{iD}}$ & $w_{\mathrm{iD}}$ & $\mathrm{p}<0,01$ \\
\hline & tak & 7 & $10,94 \%$ & 54 & $55,10 \%$ & \multirow{2}{*}{0,000000} \\
\hline & nie & 57 & $89,06 \%$ & 44 & $44,90 \%$ & \\
\hline \multirow{3}{*}{$\begin{array}{l}\text { Porównanie } \\
\text { grup Ś-D }\end{array}$} & odpowiedź & $n_{\mathrm{i} \hat{\mathrm{S}}}$ & $w_{\mathrm{i} \hat{\mathrm{S}}}$ & $n_{\mathrm{iD}}$ & $w_{\mathrm{iD}}$ & $\mathrm{p}<0,01$ \\
\hline & tak & 8 & $24,24 \%$ & 54 & $55,10 \%$ & \multirow{2}{*}{0,001066} \\
\hline & nie & 25 & $75,76 \%$ & 44 & $44,90 \%$ & \\
\hline
\end{tabular}

Źródło: opracowanie wtasne 
W przedsiębiorstwach małych (rys. 3) zaledwie w co 10 podmiocie prowadzone są akcje popularyzujące bezpieczeństwo pracy. W przypadku podmiotów średnich taką aktywność wykazało 25\% firm, a dla jednostek dużych ponad połowa $(55,1 \%)$ podejmuje aktywności na rzecz popularyzacji bhp.

Wyniki zaprezentowane w tabeli 3 oraz rysunku 3 pozwalają wnioskować o słuszności hipotezy $\mathrm{H} 1$.

\section{Uwagi i pomysły w obszarze bhp zgłaszane przez pracowników}

Kolejnym zagadnieniem objętym badaniem była analiza zgłaszania przez pracowników uwag/sugestii/pomysłów w obszarze bhp. Ankietowani mieli do wyboru trzy opcje:

1. Pracownicy nie zgłaszają uwag/pomysłów.

2. Zgłaszane przez pracowników uwagi/pomysły nie są przyjmowane/analizowane przez przełożonych/kierownictwo.

3. Zgłaszane przez pracowników uwagi/pomysły są przyjmowane/analizowane przez przełożonych/kierownictwo. Strukturę uzyskanych odpowiedzi prezentuje rysunek 4 .

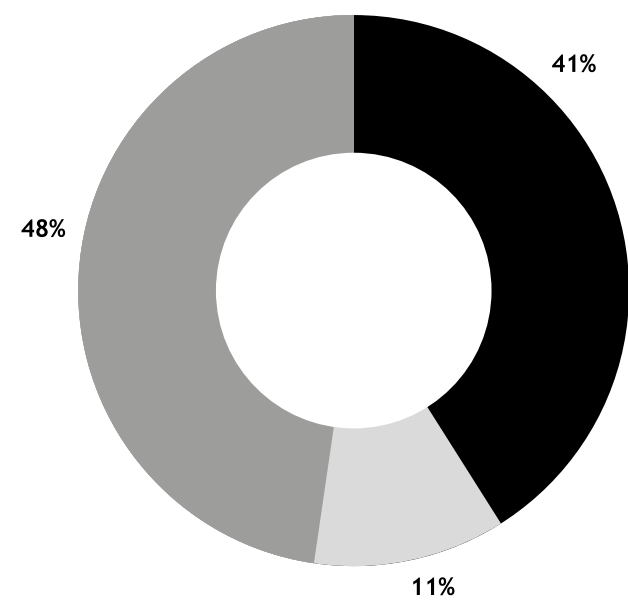

$\begin{aligned} & \text { Zgłaszane przez pracowników } \\ & \text { uwagi/pomysły są }\end{aligned}$
$\begin{aligned} & \text { Pracownicy nie zgłaszają } \\ & \text { przyjmowane/analizowane }\end{aligned}$
przez przełożonych/kierownictwo
Zgłaszane przez pracowników
uwagi/pomysły nie są
przyjmowane/analizowane
przez przełożonych/kierownictwo

Rys. 4. Aktywność pracowników i pracodawców w zakresie zgłaszanych uwag i pomystów w obszarze bhp Źródło: opracowanie własne

Nieco ponad połowa spośród wszystkich 195 badanych (rys. 4) potwierdziła fakt zgłaszania uwag i pomysłów w zakresie bhp. W części przypadków (41\%) zgłoszenia pracownicze są przyjmowane przez przełożonych, poddawane ocenie, dyskusji, analizie, co spotykało się z bardzo dobrym przyjęciem przez podwładnych, i niewątpliwie sprzyja budowaniu kultury bezpieczeństwa w organizacji. Niestety, w pozostałych przypadkach (11\%) pracownicy zgłaszają pomysły i uwagi w odniesieniu do poprawy bhp w miejscu pracy, jednak przełożeni nie dokonują ich analizy, przyjmując postawę pasywną, co może być czynnikiem demotywującym pracowników do dalszych takich działań.

Należy podkreślić, że liczba respondentów deklarujących zgłaszanie uwag/pomysłów w obszarze bhp $(\mathrm{n}=102)$ jest znacząco wyższa niż w przypadku poprzedniego zagadnienia, dotyczącego form popularyzacji na rzecz bhp (rys. 1), gdzie jedynie 15 osób wskazało takie działania. Oznaczać to może, że zgłaszanie uwag/pomysłów w obszarze bhp nie jest utożsamiane przez pracowników z popularyzacją bezpieczeństwa i higieny pracy. Większość badanych kojarzy to raczej z formą komunikacji z przełożonymi.

Dokonując bardziej szczegółowej analizy tego zagadnienia, przeprowadzono test zależności $\chi^{2}$ oraz porównano grupy firm małych, średnich i dużych $\mathrm{z}$ wykorzystaniem testu parametrycznego o równości wskaźników struktury. Tabele kontyngencji oraz statystyki porównawcze przedstawiają tabele 4 oraz 5 .

Otrzymana wartość statystyki $\chi^{2}=41,31$ oraz wyznaczona dla niej wartość $\mathrm{p}<<0,01$ wskazują na istnienie statystycznie istotnej zależności pomiędzy wielkością przedsiębiorstwa a aktywnością w obszarze zgłaszania uwag/pomysłów pracowników do bhp.

Jak wynika z rysunku 5, odsetek osób zgłaszających uwagi/pomysły w obszarze bhp w firmach dużych jest kilkukrotnie wyższy niż w firmach małych i średnich. O ile obliczone statystyki pozwalają z prawdopodobieństwem 99\% stwierdzić brak istnienia różnic w odpowiedziach pomiędzy firmami małymi i średnimi, to przedsiębiorstwa duże zachowują się istotnie inaczej. W dużych organizacjach poziom aktywności pracowników w tym obszarze jest znacznie wyższy niż w pozostałych grupach. Kierownictwo dużych przedsiębiorstw nie podejmuje aktywności odnośnie do zgłoszonych przez podwładnych uwag zaledwie w $5 \%$.

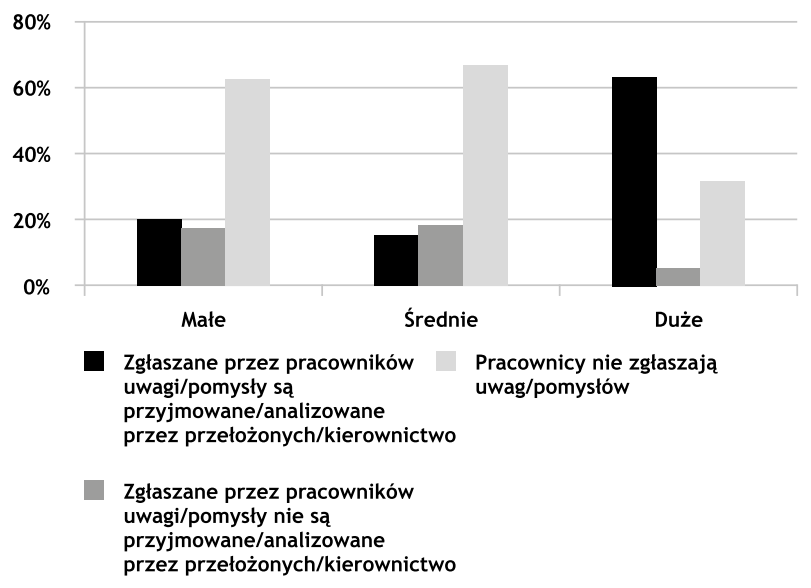

Rys. 5. Interpretacja graficzna aktywności pracowników i pracodawców w zakresie zgłaszanych uwag i pomystów w obszarze bhp w aspekcie wielkości organizacji

Źródło: opracowanie własne

Wielkość organizacji determinuje zatem aktywność pracowników i pracodawców w obszarze zgłaszania i przyjmowania/analizowania uwag i pomysłów bhp, co broni słuszności hipotezy H2. 
Tabela 4. Tabela kontyngencji i statystyka x² aktywności pracowników i pracodawców w zakresie zgłaszanych uwag i pomystów w obszarze bhp a wielkość przedsiębiorstwa

\begin{tabular}{|c|c|c|c|c|}
\hline Wielkość firmy & $\begin{array}{l}\text { Pracownicy nie } \\
\text { zgłaszają uwag/ } \\
\text { pomysłów }\end{array}$ & $\begin{array}{l}\text { Zgłaszane przez pracowników } \\
\text { uwagi/pomysły nie } \\
\text { są przyjmowane/analizowane } \\
\text { przez przełożonych/ } \\
\text { kierownictwo }\end{array}$ & $\begin{array}{c}\text { Zgłaszane przez } \\
\text { pracowników uwagi/ } \\
\text { pomysły są przyjmowane/ } \\
\text { analizowane przez } \\
\text { przełożonych/kierownictwo }\end{array}$ & Suma \\
\hline Małe & 40 & 11 & 13 & 64 \\
\hline Średnie & 22 & 6 & 5 & 33 \\
\hline Duże & 31 & 5 & 62 & 98 \\
\hline Suma & 93 & 22 & 80 & 195 \\
\hline statystyka & \multicolumn{2}{|r|}{ Chi-kwadrat } & df & $\mathrm{p}$ \\
\hline $\mathrm{Chi}^{\wedge} 2$ Pearsona & \multicolumn{2}{|r|}{41,31444} & $\mathrm{df}=4$ & $\mathrm{p}=, 00000$ \\
\hline
\end{tabular}

Źródto: opracowanie wtasne

Tabela 5. Zaangażowanie pracowników $w$ aspekcie zgtaszania uwag/pomystów bhp - analiza porównawcza $\left(n_{i M}, n_{i j}, n_{i D}-\right.$ liczba odpowiedzi, $w_{i M}, w_{i s}, w_{i D}-$ wskaźnik struktury odpowiednio dla grup $M, S$ oraz D)

\begin{tabular}{|c|c|c|c|c|c|c|}
\hline \multirow{4}{*}{$\begin{array}{l}\text { Porównanie } \\
\text { grup M-Ś }\end{array}$} & odpowiedź & $\mathrm{n}_{\mathrm{iM}}$ & $\mathrm{w}_{\mathrm{iM}}$ & $\mathrm{n}_{\mathrm{i} \hat{s}}$ & $\mathrm{w}_{\mathrm{i} \dot{\hat{s}}}$ & $\mathrm{p}$ \\
\hline & Pracownicy nie zgłaszają uwag/pomysłów & 40 & $62,50 \%$ & 22 & $66,67 \%$ & 0,342794 \\
\hline & $\begin{array}{l}\text { Zgłaszane przez pracowników uwagi/pomysły nie są przyjmowane/ } \\
\text { analizowane przez przełożonych/kierownictwo }\end{array}$ & 11 & $17,19 \%$ & 6 & $18,18 \%$ & 0,451435 \\
\hline & $\begin{array}{l}\text { Zgłaszane przez pracowników uwagi/pomysły są przyjmowane/ } \\
\text { analizowane przez przełożonych/kierownictwo }\end{array}$ & 13 & $20,31 \%$ & 5 & $15,15 \%$ & 0,267805 \\
\hline \multirow{4}{*}{$\begin{array}{l}\text { Porównanie } \\
\text { grup M-D }\end{array}$} & odpowiedź & $\mathrm{n}_{\mathrm{iM}}$ & $\mathrm{w}_{\mathrm{iM}}$ & $\mathrm{n}_{\mathrm{iD}}$ & $\mathrm{w}_{\mathrm{iD}}$ & $\mathrm{p}<0,01$ \\
\hline & Pracownicy nie zgłaszają uwag/pomysłów & 40 & $62,50 \%$ & 31 & $31,63 \%$ & 0,000054 \\
\hline & $\begin{array}{l}\text { Zgłaszane przez pracowników uwagi/pomysły nie są przyjmowane/ } \\
\text { analizowane przez przełożonych/kierownictwo }\end{array}$ & 11 & $17,19 \%$ & 5 & $5,10 \%$ & 0,005859 \\
\hline & $\begin{array}{l}\text { Zgłaszane przez pracowników uwagi/pomysły są przyjmowane/ } \\
\text { analizowane przez przełożonych/kierownictwo }\end{array}$ & 13 & $20,31 \%$ & 62 & $63,27 \%$ & 0,000000 \\
\hline \multirow{4}{*}{$\begin{array}{l}\text { Porównanie } \\
\text { grup Ś-D }\end{array}$} & odpowiedź & $\mathrm{n}_{\mathrm{i} \hat{S}}$ & $\mathrm{w}_{\mathrm{i} \hat{\mathrm{S}}}$ & $\mathrm{n}_{\mathrm{iD}}$ & $\mathrm{w}_{\mathrm{iD}}$ & $\mathrm{p}<0,01$ \\
\hline & Pracownicy nie zgłaszają uwag/pomysłów & 22 & $66,67 \%$ & 31 & $31,63 \%$ & 0,00019 \\
\hline & $\begin{array}{l}\text { Zgłaszane przez pracowników uwagi/pomysły nie są przyjmowane/ } \\
\text { analizowane przez przełożonych/kierownictwo }\end{array}$ & 6 & $18,18 \%$ & 5 & $5,10 \%$ & 0,00955 \\
\hline & $\begin{array}{l}\text { Zgłaszane przez pracowników uwagi/pomysły są przyjmowane/ } \\
\text { analizowane przez przełożonych/kierownictwo }\end{array}$ & 5 & $15,15 \%$ & 62 & $63,27 \%$ & 0,00000 \\
\hline
\end{tabular}

Źródto: opracowanie wtasne

\section{Podsumowanie}

B adania wykazały, że pracodawcy niechętnie wykorzystają działania popularyzacyjne w obszarze bhp (tylko 35\% spośród 195 organizacji), trzymając się zapewne tradycyjnych, sformalizowanych prawnie działań, tj. szkoleń bhp, opracowania instrukcji bhp, ocen ryzyka zawodowego. Stanowi to potwierdzenie praktyk dostrzeżonych przez innych autorów (Simpson, 2002; Lloyd i Roen, 2002), którzy zwrócili uwagę, że bhp jest wspólnotą praktyki, a nie instrukcją czy innego rodza- ju dokumentem. Inicjowanie i rozwijanie na terenie zakładu różnych form popularyzacji problematyki bhp i ergonomii należy do ustawowych obowiązków pracowników służb bhp (Rozporządzenie, 2004). Brak jakichkolwiek inicjatyw w większości badanych przedsiębiorstw pośrednio świadczy o niewywiązywaniu się z obowiązków pracowników służb bhp, którzy, pełniąc $\mathrm{w}$ firmie funkcje kontrolno-doradcze, nie są należytym wsparciem dla pracodawcy.

Najczęstszą formą popularyzacji bhp są: zgłaszanie przez pracowników uwag, sugestii, pomysłów na rzecz 
bhp, organizowanie konkursów bhp, dodatkowych szkoleń bhp oraz akcji informacyjno-plakatowych.

Zaledwie $\mathrm{w}$ co piątym przedsiębiorstwie $(\mathrm{n}=35$, $18 \%)$ stosowany jest system kar i nagród w motywowaniu pracowników do działań na rzecz bhp, choć zdecydowaną większość stanowią nagrody (finansowe, rzeczowe, pochwały, punkty $\mathrm{w}$ ocenie pracowniczej). Te pozytywne wyniki pozostają pozornie w sprzeczności z innymi badaniami (Gołembski i in., 2016; Wadick, 2010) przeprowadzonymi wyłącznie w sektorze budownictwa. Należy zauważyć, że w badaniach realizowanych przez autorów udział brali reprezentanci większości sektorów gospodarki. Pogłębiona analiza podmiotów stosujących kary jako motywatory bhp wykazała, iż były to wyłącznie firmy budowlane. Zatem niniejsze badania potwierdzają sektorowe uwarunkowania $\mathrm{w}$ motywowaniu na rzecz poprawy bezpieczeństwa, zauważone przez wspomnianych badaczy.

Badania wykazały również istnienie statystycznie istotnego związku pomiędzy wielkością organizacji a częstością podejmowanych wysiłków na rzecz popularyzacji bhp. Firmy małe podejmują takie działania znacznie rzadziej niż podmioty średnie i duże.

Zaangażowanie pracowników w sprawy bhp, odzwierciedlone poprzez zgłaszanie uwag/pomysłów bhp przełożonym $\mathrm{w}$ przedsiębiorstwach dużych, jest istotnie statystycznie wyższe niż w firmach małych i średnich. Podobnie, odzew kadry kierowniczej w postaci poddawania dyskusji, ocenie, analizie, zgłoszonych problemów pracowniczych jest na wyższym poziomie niż $\mathrm{w}$ firmach średnich i małych. Kierownictwo daje informację zwrotną pracownikom w ponad $90 \%$ przypadków.

Badanie nie jest pozbawione ograniczeń. Po pierwsze zgromadzony materiał badawczy, ze względu na wygodny dobór próby nie odzwierciedla struktury zbiorowości generalnej. Nielosowość próby, mimo dość znaczącej liczebności, ogranicza uogólnianie wyników. Ponadto dane uzyskane w wywiadach nie zostały zweryfikowane poprzez obserwację własną na terenie firmy, co również ogranicza zakres wyników. Przeprowadzone badanie stanowić powinno wstęp do dalszej analizy zjawiska, które warto rozwijać zwłaszcza w kontekście uwarunkowań sektorowych, oraz zatrudniania pracowników wielokulturowych. Odnotowywany w Polsce wzrost zatrudnienia cudzoziemców - głównie z Ukrainy (GUS 2018a) wymaga elastyczności przedsiębiorców w doborze form i środków popularyzacji bhp wśród pracowników ze względu chociażby na utrudnioną formę komunikacji (bariery językowe).

\footnotetext{
dr inż. Katarzyna Boczkowska

Politechnika Łódzka

Wydział Zarządzania i Inżynierii Produkcji

ORCID: 0000-0001-8555-7817

e-mail: katarzyna.boczkowska@p.lodz.pl
}

\section{dr inż. Konrad Niziołek \\ Politechnika Łódzka \\ Wydział Zarządzania i Inżynierii Produkcji \\ ORCID: 0000-0002-9232-8868 \\ e-mail: konrad.niziolek@p.lodz.pl}

\section{Przypis}

1) K. Niziołek przedstawił również wyniki badań dotyczące poziomu zaangażowania pracowników w obszarze bhp w kontekście wdrożonego systemu zarządzania na Konferencji MASEP 2018, Uniwersytet Łódzki.

\section{Bibliografia}

[1] Boczkowska K., Niziołek K. (2018), Partycypacja pracowników w zakresie bhp - koncepcja metody pomiaru, „Społeczeństwo i Edukacja”, Nr 29(2), s. 77-86.

[2] Cagno E., Micheli G.J.L., Perotti S. (2011), Identification of OHS - Related Factors and Interactions among Those and OHS Performance in SMEs, „Safety Science”, Vol. 49, No. 2, pp. 216-225.

[3] CDC (2019), Centers for Disease Control and Prevention, Workplace Health Model, https://www.cdc.gov/workplacehealthpromotion/model/index.html, access date: 19.01.2019.

[4] Champoux D., Brun J. (2003), Occupational Health and Safety Management in Small Enterprises: an Overview of the Situation and Avenues for Intervention and Research, "Safety Science”, Vol. 41, No. 4, pp. 301-318.

[5] Du Plessis K., Cronic D., Corney T., Green E. (2013), Australian Blue-collar Men's Health and Well-being: Contextual Issues for Workplace Health Promotion Interventions, „Health Promotion Practice”, Vol. 14, No. 5, pp. 715-720.

[6] Dudovskiy J. (2018), The Ultimate Guide To Writing A Dissertation In Business Studies: A Step by Step Approach, http://research-methodology.net/about-us/ebook/, access date: 19.01.2019.

[7] Ejdys J. (2010), Kształtowanie kultury bezpieczeństwa $i$ higieny pracy $w$ organizacji, Oficyna Wydawnicza Politechniki Białostockiej, Białystok.

[8] Eurofound (2015), Eurofound Third European Company Survey - Overview Report: Workplace Practices - Patterns, Performance and Well-Being, Publications Office of the EU, Luxembourg: https://www.eurofound.europa. $\mathrm{eu} /$ publications/report/2015/working-conditions-industrial-relations/third-european-company-survey-overview-report-workplace-practices-patterns-performance-and-well, access date: 20.01.2019.

[9] European Agency (2010), European Survey of Enterprises on New and Emerging Risks. Managing Safety and Health at Work, European Agency for Safety and Health at Work (EU-OSHA), Luxembourg.

[10] Fabiano B., Curro F., Pastorino R. (2004), A Study of the Relationship between Occupational Injuries and Firm Size and Type in the Italian Industry, „Safety Science”, Vol. 42, No. 7, August, pp. 587-600. 
[11] Gembalska A. (2017), Improvement of the Work Safety Management System in Hard Coal Mining with Special Reference to the Problem of Workers Participation, Section Exploration and Mining, 17th International Multidisciplinary Scientific GeoConference SGEM.

[12] Gołembski M., Sobański P., Wojtkowiak G. (2016), Employee Motivations in Maintaining Occupational Health and Safety (OHS) Compliance: Research on Nine Construction Firms in Poland, „Global Management Journal”, Vol. 8, No. 1, pp. 94-100.

[13] GUS (2018a), Zezwolenia na prace cudzoziemców w Polsce w 2017 r., https://stat.gov.pl/obszary-tematyczne/ rynek-pracy/opracowania/zezwolenia-na-prace-cudzoziemcow-w-polsce-w-2017-r-,18,1.html, data dostępu: $19.01 .2019 \mathrm{r}$.

[14] GUS (2018b), Wypadki przy pracy w 2017 r., https://stat. gov.pl/obszary-tematyczne/rynek-pracy/warunki-pracy-wypadki-przy-pracy/wypadki-przy-pracy-w-2017-r-dane-wstepne,3,30.html, data dostępu: 19.01.2019 r.

[15] Hasle P., Limborg H.J. (2006), A Review of the Literature on Preventive Occupational Health and Safety Activities in Small Enterprises, „Industrial Health”, Vol. 44, No. 1, pp. 6-12.

[16] Kopertyńska M.W. (2008), Motywowanie pracowników - teoria i praktyka, Placet, Warszawa.

[17] Lai D.N.C., Liu M., Ling F.Y.Y. (2011), A Comparative Study on Adopting Human Resource Practices for Safety Management on Construction Projects in the United States and Singapore, „International Journal of Project Management", Vol. 29, No. 8, pp. 1018-1032.

[18] Lloyd M., Roen K. (2002), What is Safety Knowledge? [in:] M. Lloyd (ed.), Occupational Health and Safety in NZ: Contemporary Social Research, Dunmore Press, Palmerston North, pp. 135-158.

[19] Milczarek M. (2002), Kultura bezpieczeństwa pracy, Wyd. Centralny Instytut Ochrony Pracy, Warszawa.

[20] Pabian A. (2008), Promocja: Nowoczesne środki i formy, Monografia, Centrum Doradztwa i Informacji Difin, Warszawa.

[21] Piratheepan U., Pushpanathan A. (2013), Impact of Promotional Strategies on Brand Awareness; A Study on Milk Powder Brands in Nuwaraeliya District, „IFRSA Business Review", Vol. 3, No. 4, pp. 268-272.

[22] Reason J. (1990), Human Error, Cambridge University Press, New York.

[23] Ricci F., Chiesi A., Bisio C., Panari Ch., Pelosi A. (2016), Effectiveness of Occupational Health and Safety Training. A Systematic Review with Meta-analysis, "Journal of Workplace Learning”, Vol. 28, No. 6, pp. 355-377.

[24] Rozporządzenie Rady Ministrów z dnia 2 listopada 2004 r. w sprawie służby bezpieczeństwa i higieny pracy.

[25] Simpson T. (2002), Bodies on the Floor: Representations, Existence, and Involvement in the Tranz Rail Ministerial Inquiry, [in:] M. Lloyd (ed.), Occupational Health and Safety in NZ: Contemporary Social Research, Dunmore Press, Palmerston North, pp. 177-197.

[26] Sørensen O.H., Hasle P., Bach E. (2007), Working in Small Enterprises - Is There a Special Risk? „Safety Science", Vol. 45, No. 10, pp. 1044-1059.
[27] Targoutzidis A., Koukoulaki T., Schmitz-Felten E., Kuhl K., Hengel K.M.O., Rijken E., Van den Broek K., Klüser R. (2014), The Business Case for Safety and Health at Work: Cost-Benefit Analyses of Interventions in Small and Medium - Sized Enterprises - Study, Publications Office of the European Union, Luxembourg: https:// publications.europa.eu/en/publication-detail/-/publication/8e9e23ea-2270-4d51-8553-94152e503afd, access date: 20.01.2019.

[28] Vecchio-Sadus A.M., Griffiths S. (2004), Marketing Strategies for Enhancing Safety Culture, „Safety Science”, Vol. 42, No. 7, pp. 601-619.

[29] Wadick P., (2010), Safety Culture among Subcontractors in the Domestic Housing Construction Industry, „Structural Survey", Vol. 28, No. 2, pp. 108-120.

[30] Werenowska A. (2016), Narzędzia marketingowe w promocji biura turystycznego, „Turystyka i Rozwój Regionalny", Nr 5, s. 139-147.

[31] Znajmiecka-Sikora M. (2014), Ocena kultury bezpieczeństwa w sektorze MŚP na podstawie badań przedsiębiorstw $z$ regionu łódzkiego, [w:] A. Juźwicka i in. (red.), Nowe spojrzenie na kulturę organizacyjna, Monografie, Wyd. Politechniki Łódzkiej, Łódź, s. 53-62.

[32] Zohar D., Luria G. (2003), The Use of Supervisory Practices as Leverage to Improve Safety Behavior: A Cross-level Intervention Model, „Journal of Safety Research”, Vol. 34, No. 5, pp. 567-577.

\section{Popularisation of Health and Safety at Work in the Context of Organisation's Size}

\section{Summary}

The aim of this paper is to identify the level and forms of organisation's activity in the field of popularising knowledge about health and safety and to shape safetypromoting attitudes. The study was conducted using the PAPI method on a group of 195 representatives of organisations. The research showed a relatively low activity of the organisations in the field of health and safety promotion, only $1 / 3$ of companies take such activities. The most common form of health and safety awareness was submitting by employees comments / suggestions / ideas in the area of health and safety, organising health and safety competitions, additional training in this area as well as information and poster campaigns. A relatively small group of entrepreneurs applies a system of penalties and prizes, although definitely more often we can encounter a positive reinforcement (financial rewards, non-cash prizes, praise, points). Statistical analysis showed significant differences between the size of the organisation and the frequency of efforts to promote and motivate employees to comply with health and safety regulations. Small companies take such measures much less frequently than medium and large organisations.

\section{Keywords}

OHS, popularization of health and safety, SME 